\title{
ASO Author Reflections: the Role of Dispositional Optimism for Better Health-Related Quality of Life after Esophageal Cancer Surgery
}

\author{
Yangjun Liu, $\mathrm{MD}^{\mathbf{1}}$, and Pernilla Lagergren, $\mathrm{PhD}^{1,2}$ \\ ${ }^{1}$ Department of Molecular Medicine and Surgery, Karolinska Institutet, Karolinska University Hospital, Stockholm, \\ Sweden; ${ }^{2}$ Department of Surgery and Cancer, Imperial College London, London, UK
}

\section{PAST}

As the mainstay of curative treatment for esophageal cancer, surgery increases survival but entails impaired health-related quality of life (HRQL). ${ }^{1}$ To improve postoperative HRQL, it is important to identify its predictors. The already identified sociodemographic and clinical predictors cannot fully explain the variation of HRQL after esophageal cancer surgery, suggesting that other factors may also play a role. Dispositional optimism, a personality trait, has been found to be associated with HRQL in patients with other subtypes of cancer., ${ }^{2,3}$ However, no such studies have been conducted in patients with esophageal cancer.

\section{PRESENT}

The current Swedish nationwide longitudinal study $^{4}$ assessed whether higher dispositional optimism predicted better HRQL after esophageal cancer surgery. Patients in this study were categorized into four groups with hierarchical dispositional optimism levels. Postoperative HRQL was measured using the European Organization for Research and Treatment of Cancer (EORTC) Quality of Life Questionnaire-Core 30 (QLQ-C30) and Quality of Life Questionnaire-Esophago-Gastric module 25 (QLQOG25). This study found that patients with higher

(C) The Author(s) 2021

First Received: 6 April 2021

Accepted: 10 April 2021;

Published Online: 26 April 2021

$\mathrm{P}$. Lagergren, $\mathrm{PhD}$

e-mail: pernilla.lagergren@ki.se dispositional optimism reported better global quality of life, emotional function, social function, and self-perceived body image, and fewer self-reported problems in pain, dyspnea, diarrhea, anxiety, dry mouth, trouble with taste, and worry about weight loss after esophageal cancer surgery. The predictive effect of dispositional optimism may help identify patients with high risk of suffering from poor HRQL recovery after esophageal cancer surgery, and thus may lead to timely and tailored interventions to improve postoperative HRQL.

\section{FUTURE}

Studies elucidating potential effective interventions to improve postoperative $\mathrm{HRQL}$ are warranted. It might be worth examining whether increasing dispositional optimism could improve postoperative HRQL. Identifying the potential modifiable mediators between dispositional optimism and HRQL may also be valuable because some potential mediators such as coping strategy and social support may be easier to be modified than dispositional optimism. In addition, interventions to prevent or relieve psychological distress may also help improve HRQL after esophageal cancer surgery. ${ }^{5}$

FUNDING Open access funding provided by Karolinska Institutet.

DISCLOSURE The authors declare no conflicts of interest.

OPEN ACCESS This article is licensed under a Creative Commons Attribution 4.0 International License, which permits use, sharing, adaptation, distribution and reproduction in any medium or format, as long as you give appropriate credit to the original author(s) and the source, provide a link to the Creative Commons licence, and indicate if changes were made. The images or other third party material in this 
article are included in the article's Creative Commons licence, unless indicated otherwise in a credit line to the material. If material is not included in the article's Creative Commons licence and your intended use is not permitted by statutory regulation or exceeds the permitted use, you will need to obtain permission directly from the copyright holder. To view a copy of this licence, visit http://creativecommons. org/licenses/by/4.0/.

\section{REFERENCES}

1. Lagergren P, Avery KN, Hughes R, et al. Health-related quality of life among patients cured by surgery for esophageal cancer. Cancer. 2007;110(3):686-93.

2. Allison PJ, Guichard C, Gilain L. A prospective investigation of dispositional optimism as a predictor of health-related quality of life in head and neck cancer patients. Qual Life Res. 2000;9(8):951-60.
3. Zenger M, Brix C, Borowski J, Stolzenburg JU, Hinz A. The impact of optimism on anxiety, depression and quality of life in urogenital cancer patients. Psycho-Oncol. 2010;19(8):879-86.

4. Liu Y, Pettersson E, Schandl A, Markar S, Johar A, Lagergren P. Higher dispositional optimism predicts better health-related quality of life after esophageal cancer surgery: a nationwide populationbased longitudinal study. Ann Surg Oncol. 2021. https://doi.org/ 10.1245/s10434-021-10026-w.

5. Liu YJ, Schandl A, Markar S, Johar A, Lagergren P. Psychological distress and health-related quality of life up to 2 years after oesophageal cancer surgery: nationwide population-based study. BJS Open. 2021;5(1):zraa038.

Publisher's Note Springer Nature remains neutral with regard to jurisdictional claims in published maps and institutional affiliations. 